\title{
Achieving Enzyme Stability Using a Simple Fabrication Procedure: The Alcohol Dehydrogenase Example
}

\author{
I. Ribau and E. Fortunato \\ Departamento de Ciências dos materiais, Faculdade de Ciências and Tecnologia, Universidade Nova de Lisboa, Campus de \\ Caparica, Caparica 2829-516, Portugal
}

\begin{abstract}
The use of screen-printing biosensors has been updated in this article as a tool to analyze the electron transfer process involving redox proteins or enzymes. The aim of this research was to fabricate a simple apparatus which allowed the use of the enzymes (in the solid state) to maintain their stability. To prove this concept an enzyme in the solid state was mixed with the carbon ink and this mixture was used to print the working electrode. We choose as proving the alcohol dehydrogenase. The first reason is because it metabolizes the alcohol, which can be present in biological samples of blood, saliva and urine and also in the beverage; the second is that this enzyme is still a challenge to electrochemistry due to having lower stability in sensors. The results show that in this device the enzyme was active and stable during all the experiments and in the experimental conditions that could catalyze the ethanol to acetaldehyde. These devices have the advantage of being disposable, cheap and are easy to fabricate. And also, they do not need expensive tools to be fabricated, they only need $2 \mu \mathrm{L}$ of electrolyte or sample, and they need lower amounts of enzyme to permit electrochemical studies.
\end{abstract}

Key words: Paper biosensor, disposable, alcohol dehydrogenase, multiple use.

\section{Introduction}

The use of disposable and miniaturized biosensors that can detect subtract, like glucose and ethanol, in biological fluid or in food, with accuracy has been developed since the nineties [1-5].

The use of carbon as a base material to construct screen-printing devices have been employed, during the last decades, because it has adequate properties that allows not only its simple use as porous materials, but also it permits surface modification and is cheap [5-9]. Fabrication of paper-based devices has also been developed in the last ten years, but still it is a challenge. Paper is an environmental friend material, easily manipulated, cheap, and biocompatible; has high adaptability for analysis of different substances. These properties make paper the perfect physic base for introducing microfluidic channels and to be used in Point-of-care devices [5, 8-10]. One disadvantage of

Corresponding author: Isabel Ribau, Ph.D., researcher, research fields: biosensors and bioeletrochemistry. this apparatus is the lower electron transfer rate between biosensing elements and the electrode surface. Another important disadvantage is the interference of temperature and humidity on migration forces of liquid in microfluidic channels, which may lead to electrochemical signal variations [5].

Although there has been a great investment in analytical research methods related to dehydrogenases, only a few researchers developed sensors based on it, since the cofactor regeneration is a limitation [2] and the low enzyme stability is still a limitation factor [4]. The NAD-dependence and his free-diffusion is also a limitation to its use. Some strategies pass through a stable immobilization of the cofactor and enzyme in sol-gel matrices [11], immobilization of the enzymes and cofactor in nano-structured carbon platforms or carbon nanotubes modified electrodes [12-14], in alginate-silicate hybrid gel [15] and other polymers $[3,4,16]$.

The ADH (alcohol dehydrogenase) is a zinc-containing enzyme, usually used in the food 
industry [17]. The Saccharomyces cerevisiae produced three isoenzymes of alcohol dehydrogenase, YADH-1 (expressed during anaerobic fermentation), YADH-2 (cytoplasmic form repressed by glucose) and YADH-3 (found in mitochondria) [17]. ADH belongs to Alcohol: $\mathrm{NAD}^{+}$oxidoreductase class and structurally it is constituted by an asymmetric homotetramer with four different subunits, organized as analogous dimmers, (see in Fig. 1).

The structural analysis suggests that the dimeric subunits asymmetry of the tetramer (that provided two structures, in open and closed conformation) may be relevant for the catalytic mechanism. Some subunits present a close conformation with coenzyme bound to the catalytic site, but others subunits present an open conformation without coenzyme. Each subunit contains a "catalytic" zinc and a "structural" zinc. The active site of each subunit contains a zinc atom [18]. In the close conformation, the catalytic zinc presents a tetrahedral coordination with two reactive sulfhydryl groups of Cys-43, Cys-153, with a histidine residue (His-66) and a water molecule [18]. Baskar, Ramaswamy,
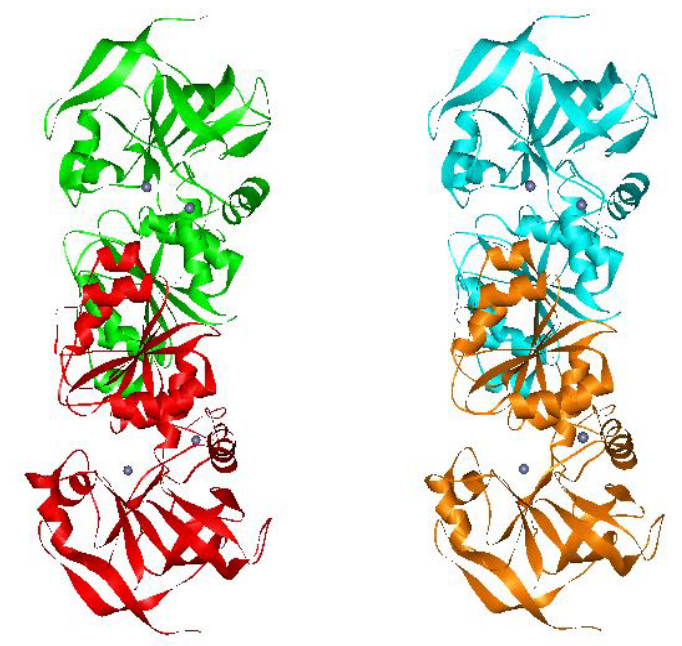

Fig. 1 Structure for ADH1 (alcohol dehydrogenase) tetramer (each subunit presents different colour) in the open conformation from yeast (Saccharomyces cerevisiae) determined by $\mathrm{X}$-ray crystallography [18]. The zinc atoms are shown as grey spheres. In the dimer, the catalytic subunits of the two subunits in open conformation are closely associated with one another. PDB code: 4 W6Z. This figure was prepared with Viewerlite program. and Plapp (2014) have proposed a mechanism by which zinc-bound water, in the close conformation, is substituted by an alcohol or aldehyde. In the open conformation zinc is coordinated with Cys-43, Cys-153, His-66, and the carboxylate of Glu-67 [18]. In this conformation the zinc coordination in the catalytic domain is inverted (relative to the classic coordination) and the active site zinc coordination is flexible, which facilitates the movements of the zinc ligands and helps the approximation of the zinc ion to Glu-67 [18]. The other zinc atom (structural zinc) is linked to four cysteine residues (97, 100, 103 and 111) and it is in an external location protected by disulphide bridges. Its function is still unclear, although it seems to have an important conformational role, by stabilizing the tertiary structure of each subunit [19]. Its removal from the enzyme did not reduce the catalytic activity, but the enzyme was more susceptible to heat denaturation [19].

This enzyme catalyses the reversible reaction [20, 21]:

$$
\begin{gathered}
\mathrm{NADH} \rightarrow \mathrm{NAD}^{+}+\mathrm{H}^{+}+2 \mathrm{e}^{-} \\
\mathrm{CH}_{3} \mathrm{CH}_{2} \mathrm{OH}+\mathrm{NAD}^{+} \rightleftarrows \mathrm{CH}_{3} \mathrm{CHO}+\mathrm{NADH}+\mathrm{H}^{+}
\end{gathered}
$$

In this reaction, the nicotinamide adenine dinucleotide hydrate $\left(\mathrm{NAD}^{+}\right)$receives the hydride ion from a reduced substrate, but at $\mathrm{pH} 7$ (neutral $\mathrm{pH}$ ) the equilibrium (2) is shifted to the left. ADH, also can use glucose and lactate as substrate, as well as it is capable to reduce substrates which make it important in biofuel cells and biobatteries [21, 22].

To analyze the presence of alcohol in drinks and its influence in the determination of glucose, we fabricated a biosensor using the alcohol dehydrogenase from Saccharomyces cerevisiae (baker's yeast). The main goal of this project was to develop biosensors that could be used to analyze the quantity of ethanol, in the presence of glucose, in the blood and alcoholic beverages, including beer, wine and spirits. These devices allow not only the study of the electron transfer process, but also the ethanol detection. 


\section{Experimental}

\subsection{Materials and Methods}

All reagents used were of analytical grade. The alcohol dehydrogenase lyophilized powder from Saccharomyces cerevisiae (Sigma-Aldrich A7011) $(\mathrm{ADH})$ was used with no further purification. This enzyme has a molecular weight $141-151 \mathrm{kDa}$, an isoelectric point between 5.4-5.8 and the optimal $\mathrm{pH}$ is reported to be in the range of 8.6 and 9.0 [17-19]. Ethanol (96\%), $\beta$-D-glucose and potassium chloride were acquired from Sigma-Aldrich. All solutions were prepared with buffer. All buffers used in this work were commercial and purchased from ROTH (Germany). The electrolyte was a buffer solution with potassium chloride $(0.1 \mathrm{M})$. The carbon ink and $\mathrm{Ag} / \mathrm{AgCl}$ ink were purchased from conductive compounds.

\subsection{Fabrication of the Biosensor}

The fabrication process of the biosensor is very simple and reproductive. It has two main parts: first is the use wax to do delimitate the microfluidic channel; the second is the screen-printing of the electrodes above the wax and of the microfluidic channels.

A Xerox Color Qube 8570 printer from Xerox was used to print the hydrophobic region of the devices. The paper used was Whatman n. ${ }^{0} 1$ chromatographic paper, and the wax was obtained from Xerox. After the wax printing, the wax was heat treated during $10 \mathrm{~s}$ in a hot plate $\left(150^{\circ} \mathrm{C}\right)$. After that, the paper, cooled at room temperature was ready to perform the screen-printing technique. The configuration system designed was a three electrode system with an $\mathrm{Ag} / \mathrm{AgCl}$ reference electrode, a carbon counter electrode and a working electrode based in carbon ink. Using a mesh the counter electrode was deposited above the hydrophobic matrix (wax). Then the mesh was removed and the device was allowed to heat at hot plate $\left(60^{\circ} \mathrm{C}\right)$ during 8 minutes. The other two electrodes had the same screen-printing treatment.

\subsection{Working Electrode Preparation}

A mixture with an enzyme in the solid state and carbon ink was prepared and used to fabricate the working electrode.

\subsection{Electrochemical Detection}

The ADH usually metabolizes ethanol to acetaldehyde in the presence of $\mathrm{NAD}^{+}$. Our experiments were performed without the addition of this cofactor to the working electrode or to the electrolyte solutions used.

During the electrochemical measurements, a drop of the interest solution $(2 \mu \mathrm{L})$ spots in the hydrophobic channel between the wax-limited zones and dispersed through the paper matrix in a few seconds, being in contact with the three electrodes. The electrochemical behaviour of each electrode was experimentally characterized through cyclic voltammetry.

All electrochemical acquisitions and measurements were performed in a Gamry ESA419 data acquisition system, using PHE 200 physical electrochemical and PV 220 physical electrochemical software coupled with a Gamry instruments (reference 600) potentiostat/galvanostat (ZRA) and the data analysis was processed by Gamry software package. All the experimental procedure is performed in normal atmosphere in the presence of oxygen.

\section{Results and Discussion}

\subsection{Electrochemistry of $A D H$ in Screen-Printing Electrodes}

Voltammetric experiments at the screen-printing sensor have been performed in the electrolyte (phosphate buffer, $\mathrm{pH}$ 7) to obtain the $\mathrm{ADH}$ electrochemical signal, in non-turnover conditions. No modification was necessary in order to achieve direct electrochemistry of $\mathrm{ADH}$. In the experiments, the electrode surface and the active site of the enzyme could be considered as a donor-acceptor pair and it is 
possible to use Markus theory to describe this electron transfer [23]. In this context it is known that the major distance between donor atom and acceptor atom, to have direct electron transfer is approximately $10 \AA$, and that the transfer occurred via an electron tunnelling mechanism [24]. This is only possible in the open conformation, where the active site is accessible, as it can be seen in the crystal structure [17, 25]. Two well defined anodic peaks and two well-defined cathodic peaks were observed in different scan rates (see in Fig. 2) .

The all peak currents vary linearly with the square root of the sweep rate between $20 \mathrm{mV} \cdot \mathrm{s}^{-1}$ and 100 $\mathrm{mV} \cdot \mathrm{s}^{-1}$ thus denoting a diffusion-controlled process. The parameters obtained for the coupled I/II were: a cathodic peak, $E_{\mathrm{p}}{ }^{\mathrm{a}}=(+65 \pm 3) \mathrm{mV}$ and an anodic peak,
$E_{\mathrm{p}}{ }^{\mathrm{c}}=(-152 \pm 8) \mathrm{mV}$, a separation of anodic to cathodic peak, $\Delta E \mathrm{p}$, of $(-218 \pm 11) \mathrm{mV}$ vs. $\mathrm{Ag} / \mathrm{AgCl}$ and a formal potential, $\mathrm{E}^{0}$, of $(-44 \pm 3) \mathrm{mV}$ vs. $\mathrm{Ag} / \mathrm{AgCl}$. A ratio of anodic to cathodic peaks current, $\left|i_{\mathrm{p}}{ }^{\mathrm{a}} / \mathrm{i}_{\mathrm{p}}{ }^{\mathrm{c}}\right|$ was also estimated at $0.45 \pm 0.03$.

For the coupled III/IV the estimated parameters were: a cathodic peak, $E_{\mathrm{p}}{ }^{\mathrm{a}}=(+315 \pm 4) \mathrm{mV}$ and an anodic peak, $E_{\mathrm{p}}{ }^{\mathrm{c}}=(+220 \pm 9) \mathrm{mV}$, a peak-to-peak separation, $\Delta E \mathrm{p}$, of $(95 \pm 5) \mathrm{mV}$ vs. $\mathrm{Ag} / \mathrm{AgCl}$ and formal potential of $E^{0,}=(268 \pm 6) \mathrm{mV}$ vs. Ag/AgCl. A ratio of anodic to cathodic peaks current, $\left|i_{\mathrm{p}}{ }^{\mathrm{a}} / \mathrm{i}_{\mathrm{p}}{ }^{\mathrm{c}}\right|$ was also estimated as $0.82 \pm 0.03$. Although $\mathrm{i}_{\mathrm{p}} / \mathrm{v}^{1 / 2}$ is independent of the scan rate, $E_{\mathrm{p}}$ varies with the scan rate and $\left|i_{\mathrm{p}}{ }_{\mathrm{p}}^{\mathrm{a}} / i_{\mathrm{p}}{ }^{\mathrm{C}}\right|$ is far from the unit. These data suggest a quasi-reversible system that it's not only controlled by diffusion, but it is also influenced by the kinetics of the electrode process.

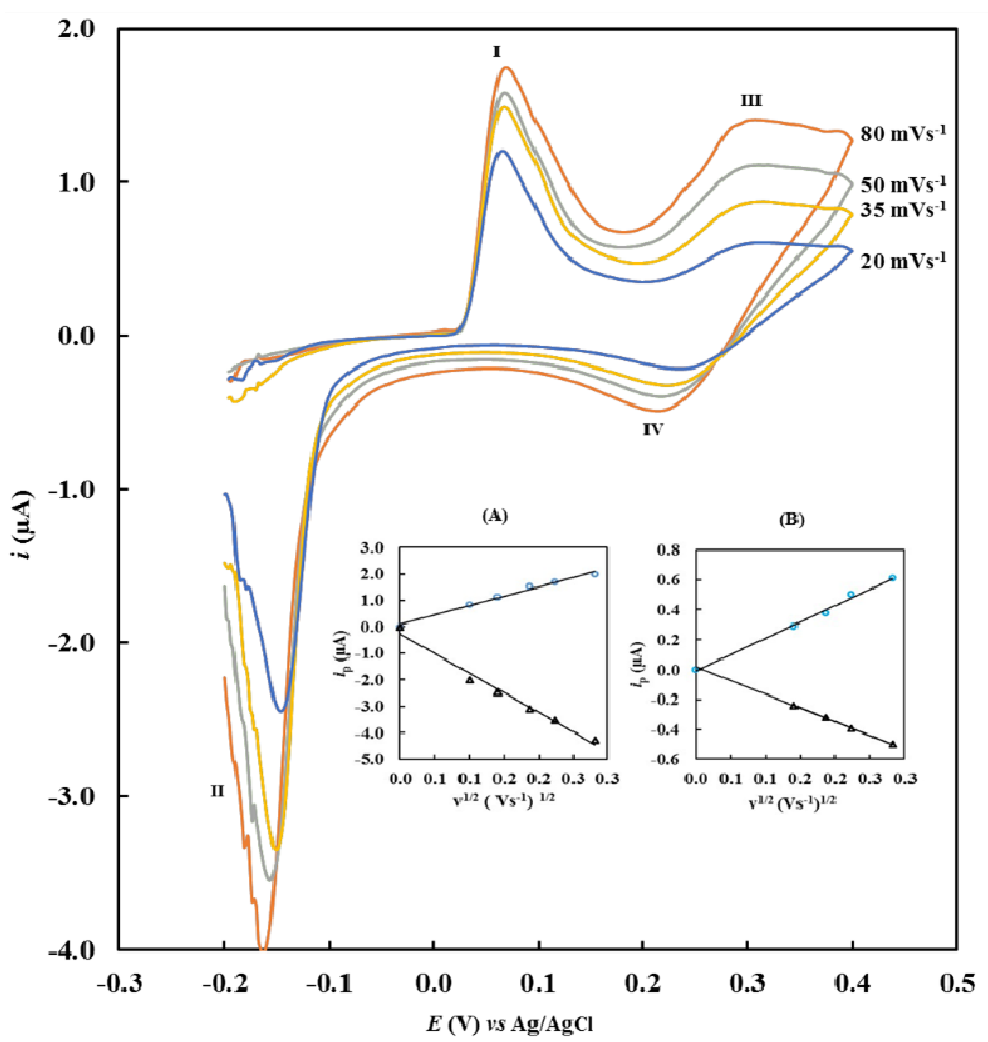

Fig. 2 Cyclic voltammograms $\left(20 \mathrm{mV} \cdot \mathrm{s}^{-1}<\mathrm{v}<100 \mathrm{mV} \cdot \mathrm{s}^{-1}\right.$ ) in a $2 \mu \mathrm{L}$ electrolyte (phosphate buffer (pH 7.0) with $\mathrm{KCl}(100 \mathrm{mM})$ ) from $-0.4 \mathrm{~V}$ to $-\mathbf{0 . 4} \mathrm{V}$, at a screen-printing electrode with a three electrodes system configuration (an $\mathrm{Ag} / \mathrm{AgCl} \mathbf{~ r e f e r e n c e}$ electrode; a carbon counter electrode; a working electrode based in carbon ink (1.0 g) with AHD (14 mg)). Insertion: Variation in cathodic $(\Delta)$ and anodic $(\circ)$ current peaks with the square root of the scan rate. Current peaks II and $I\left((\circ) i_{\mathrm{p}}{ }^{a}=2.1772 \mathrm{v}^{1 / 2}-\right.$ $\left.0.009, R^{2}=0.9939 ;(\Delta) i_{\mathrm{p}}{ }^{\mathrm{c}}=-1.8312 \mathrm{v}^{1 / 2}+0.019, R^{2}=0.9997\right)(\mathrm{A})$; Current peaks III and IV $\left((\circ) i_{\mathrm{p}}{ }^{\mathrm{a}}=7.0835 \mathrm{v}^{1 / 2}+0.0837, R^{2}=\right.$ $\left.0.9853 ;(\Delta) i_{\mathrm{p}}{ }^{\mathrm{c}}=-14.839 \mathrm{v}^{1 / 2}-0.253, \mathrm{R}^{2}=0.9829\right)(\mathrm{B})$. 


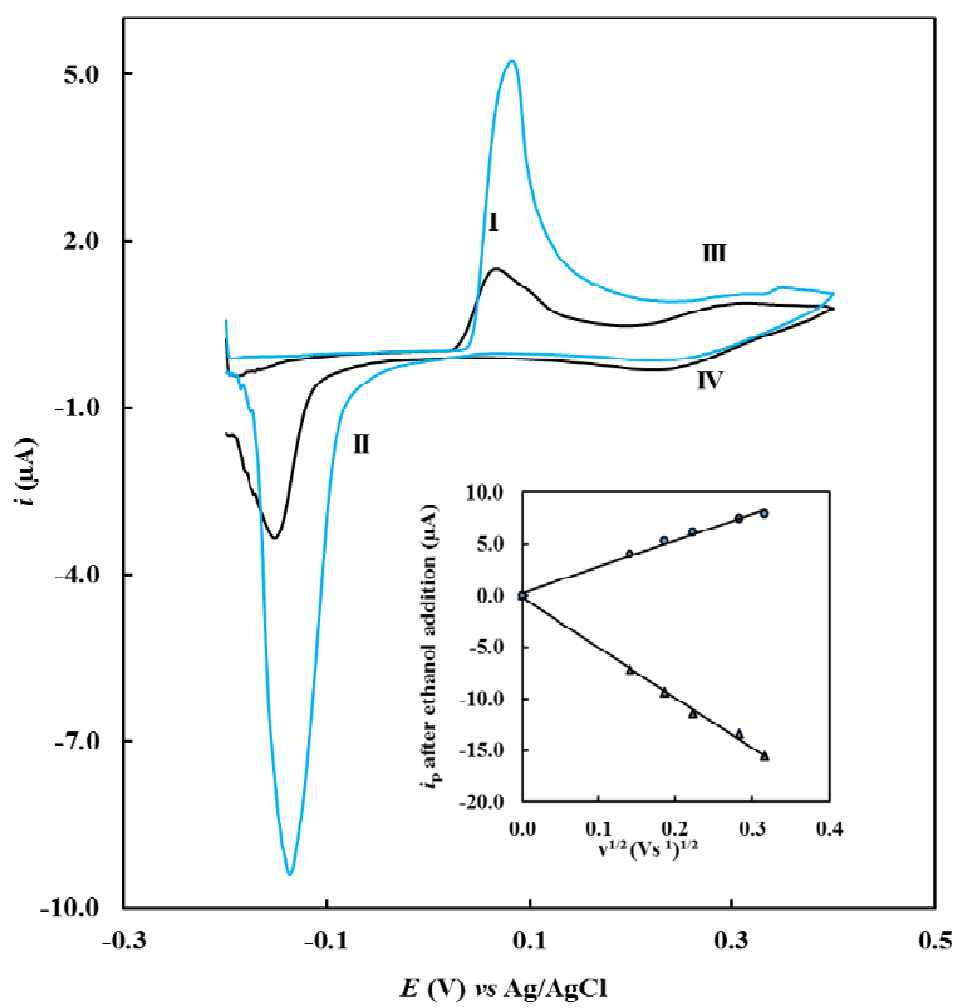

Fig. 3 Cyclic voltammograms $\left(v=35 \mathrm{mV} \cdot \mathrm{s}^{-1}\right)$ in phosphate buffer (pH 7.0) and $100 \mathrm{mM} \mathrm{KCl}$ at a screen printing electrode with a three electrode system configuration with an $\mathrm{Ag} / \mathrm{AgCl}$ reference electrode, a carbon counter electrode and a working electrode based in carbon ink (1.0 g) with AHD (14 mg) in the absence ( -$)$ and in the presence $(-)$ of ethanol (2.4\%). Insertion: Scan rate dependence of the cathodic $(\Delta)$ and anodic $(\circ)$ peak current.

To verify if we were in the presence of the active enzyme, and the peaks that correspond to the catalytic domain, we used ethanol as substrate. It was possible to see that the peaks I and II, increased in the presence of ethanol. This information permitted the identification which peak corresponds to the catalytic domain, peaks I and II, Fig. 3.

A cathodic peak, $E_{\mathrm{p}}{ }^{\mathrm{a}},(+84 \pm 3) \mathrm{mV}$ and anodic peak, $E_{\mathrm{p}}{ }^{\mathrm{c}},(-149 \pm 13) \mathrm{mV}$ appeared. A catalytic behaviour could be observed with an increase in the currents in both peaks. A midpoint potential of $(-33 \pm 6) \mathrm{mV}$, and a peak-to-peak separation of $(-233 \pm 16) \mathrm{mV}$, are obtained in agreement with the previous data.

It's possible to verify that the peaks II and I correspond to the catalytic process once they increase with the ethanol addition. We can also assume that the enzyme is not in the inactive conformation and that it has the correct conformation to catalyze ethanol. In this condition the enzyme is in the open conformation, with the active site accessible to the substrate (ethanol).

From these results, we can suggest that the cyclic voltammograms of the alcohol dehydrogenase presents an electrochemical signal corresponding to the catalytic domain and another correspondent to the structural zinc. After the application of a reduction potential $(-0.5 \mathrm{~V}$ vs. $\mathrm{Ag} / \mathrm{AgCl})$, the voltammograms shape is almost the same as in Fig. 1, but the peaks III and IV disappear and peaks I and II remain.

The effect of $\mathrm{pH}$ on ADH signal voltammetry was investigated over a range 3-10, using different buffer solution all with $\mathrm{KCl}(0.1 \mathrm{M})$. Initially a drop of electrolyte was added in the working area, and then the cyclic voltammograms at different scan rate were recorded. After that, $2 \mu \mathrm{L}$ of ethanol solution prepared in the electrolyte used before was added in the working area, and again the cyclic voltamogramas were recorded. The $\mathrm{pH}$ dependence of the formal potential in the absence and in the presence of ethanol shows an 
increase between $\mathrm{pH} 3$ and $\mathrm{pH}$, but after that, $\mathrm{pH}$ value is almost constant (see in Fig. 4).

Since the formal potential of an enzyme is related to electrostatic and hydrophobic environment, with hydrogen bonding, zinc axial ligands, zinc coordination and geometry, and solvent exposure and also with the movement of the amino acid chain in the neighbourhood of the active site, its analysis is not simple. However, it is important to highlight that upon altering the $\mathrm{pH}$ values of the medium, it is possible to analyze a $\mathrm{pKa}$ transition in the vicinity of the catalytic site related to an acid transition. In these conditions the formal potential variation with the $\mathrm{pH}$ allows $\mathrm{pKa}$ estimation from the experimental data of 4.6. This $\mathrm{pKa}$ can be attributed to glutamic acid, which presents a $\mathrm{pKa}$ of 4.4 [26]. It is important to underline that in the

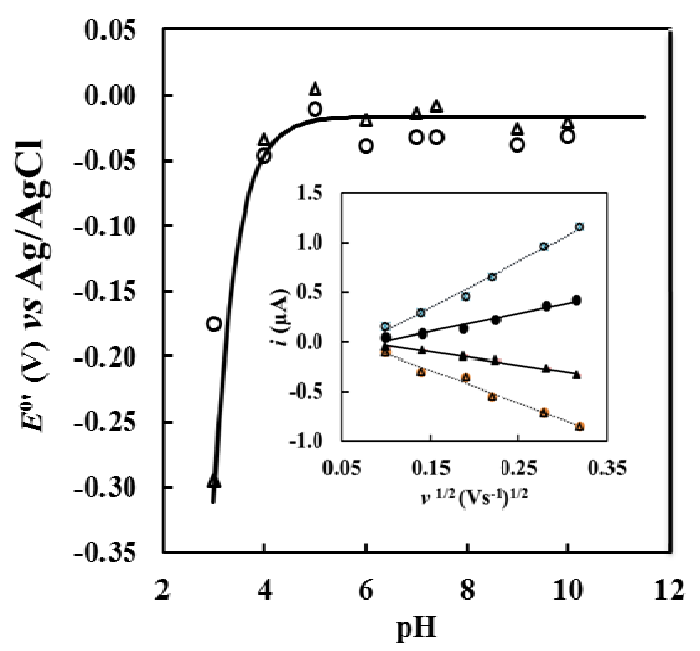

Fig. $4 \mathrm{pH}$ dependence of the formal potential in the absence $(\circ)$ and in the presence $(\Delta)$ of ethanol $(3.4 \mathrm{M})(\mathrm{pKa}$ estimated at 4.6). Cyclic voltammograms recorded in different buffer solutions with $\mathrm{KCl}(100 \mathrm{mM})(\circ)$ and with ethanol prepared in different buffer with $\mathrm{KCl}(0.1 \mathrm{M})(\Delta)$, at a screen printing electrode with a three electrode system configuration with an $\mathrm{Ag} / \mathrm{AgCl}$ reference electrode, a carbon counter electrode and a working electrode based in carbon ink (1.0 g) with AHD (14 mg). Insertion: Variation in cathodic $(\Delta)$ and anodic $(O)$ current peaks with the square root of the scan rate, acetate buffer ( $\mathrm{pH} 4)$ with $\mathrm{KCl}(0.1 \mathrm{M})$, in the absence (bold) and in the presence (light) of ethanol (3.4 M). The best fitting curves were: $(\circ) i_{\mathrm{p}}{ }^{\mathrm{a}}=4.6442 \mathrm{v}^{1 / 2}-$ $0.3549, R^{2}=0.9894 ;(\bullet) i_{\mathrm{p}}{ }^{\mathrm{a}}=1.8149 \mathrm{v}^{1 / 2}-0.1664, R^{2}=0.9749$;

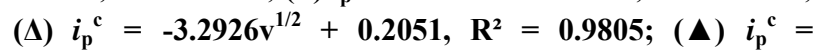
$-1.2988 v^{1 / 2}+0.0941, R^{2}=0.9861$. enzyme open conformation, the catalytic zinc is tetrahedral coordinated with Cys-43, Cys-153, His-66, and with the carboxylate of Glu-67 [18, 25]. The fact that the substitutions of Glu-67 with Gln-67 decrease the catalytic efficiency by 100 -fold [18] reflect its importance in the catalytic mechanism, corroborate the identification of the $\mathrm{pKa}$ in our experiments, and also the presence of the active and open conformation of the enzyme in the working electrode.

\subsection{ADH and Glucose}

Because glucose is present in a beverage but also in biological fluids, and our aim was to demonstrate the applicability of this sensor in multiple use, we also investigated the influence of glucose in the electrochemical signal of the enzyme at $\mathrm{pH} 5$. In a range between $25 \mathrm{mM}$ and $100 \mathrm{mM}$, in $\mathrm{pH}$, the glucose promoted an increase in the current peak seeing in Fig. 5. Below 25 mM the presence of glucose is not sense.

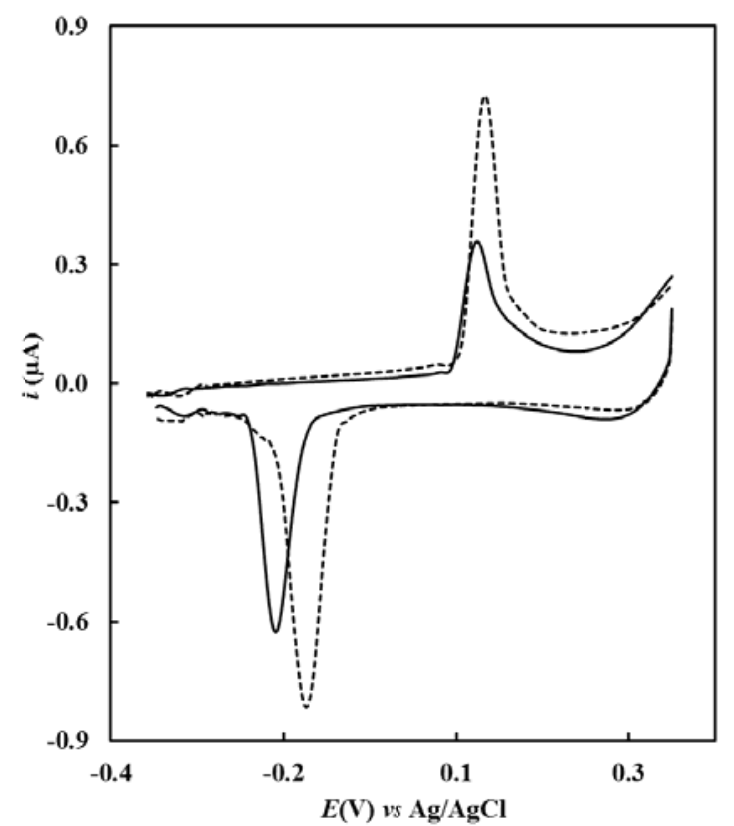

Fig. 5 Cyclic voltammograms $\left(v=50 \mathrm{mV} \cdot \mathrm{s}^{-1}\right)$ in phosphate buffer (pH 5.0) and $100 \mathrm{mM} \mathrm{KCl}$ at a screen printing electrode with three electrode system configurations with an $\mathrm{Ag} / \mathrm{AgCl}$ reference electrode, a carbon counter electrode and a working electrode based in carbon ink $(1.0 \mathrm{~g})$ with AHD (14 mg) in the absence (-) and in the presence (- - -) of glucose (63 mM). 
This result has two meanings, the first one is operational-in samples with glucose in a concentration higher than $25 \mathrm{mM}$, it will interfere with the measurements of ethanol; the second is functional-this enzyme in the open conformation can not only catalyse the ethanol but also glucose. The implication of this last finding is that it is also possible to use glucose as a substrate of the $\mathrm{ADH}$ and this system can be used to develop biofuel cells and biobatteries. This result was also reported by Wang and co-workers in 2012 [21].

\subsection{ADH and Ethanol Detection}

The ethanol detection at $\mathrm{pH} 5$ (the typical drinks/beverage $\mathrm{pH}$ ) and $\mathrm{pH} 7$ (blood, $\mathrm{pH}$ 7.4) was analyzed. This determination pretends to prove the ubiquity/utility of the fabrication procedure, which allow the stability of the enzyme and its functioning in different $\mathrm{pH}$.

$$
\text { At } \mathrm{pH} 5 \text {, the } i_{\mathrm{p}}^{\text {a catalytic }}\left(\mathrm{v}=80 \mathrm{mV} \cdot \mathrm{s}^{-1}\right) \text { varies linearly }
$$

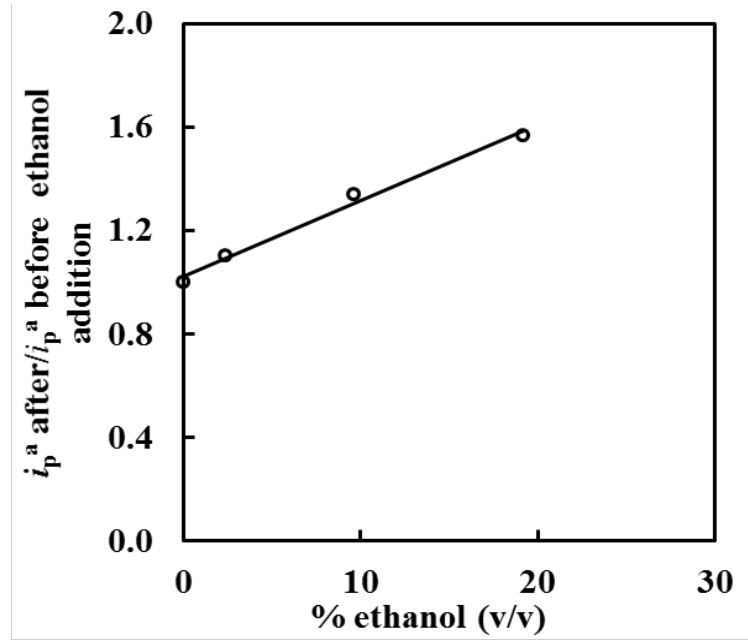

Fig. 6 Catalytic current curve variation with the ethanol concentration between $2.4 \%(\mathrm{v} / \mathrm{v})$ and $19.6 \%(\mathrm{v} / \mathrm{v})$. Cyclic voltammograms recorded in buffer solutions (pH 5) with $\mathrm{KCl}(100 \mathrm{mM})(\circ)$ and with ethanol prepared in buffer (pH 5) with $\mathrm{KCl}(0.1 \mathrm{M})$, at a screen-printing electrode with a three-electrode system configuration with an Ag/AgCl reference electrode, a carbon counter electrode and a working electrode based in carbon ink (1.0 g) with AHD (14 mg). The best curve fit in the range of $2.4 \%-19.2 \%$ are $i_{p}{ }^{\text {a cat }}$ $=0.029$ [ethanol] $+1.023, R^{2}=0.989$. Each point is the average of at least two measurements made with different screen-printing biosensors. with the ethanol concentration in the range of 2.4\%-9.6\% shown in Fig. 6.

With this sensor it will be possible to quantify the ethanol in acid samples like beverage (wine, beer) which have an ethanol concentration between $2.4 \%$ and $19.2 \%$.

The variation of the catalytic current with the ethanol at $\mathrm{pH} 7$ was also investigated. The curve obtained with standard solutions shows a linear variation in the range of $0 \%$ and $9.6 \%$, and then a higher decrease in Fig. 7.

This result shows that the sensor can also detect ethanol in samples with $\mathrm{pH}$ near 7, like blood, in the range of $2.4 \%-9.6 \%$.

Since glucose in concentration lower $25 \mathrm{mM}$ does not interfere with the biossensor, it can be used to determine the alcohol in drinks with glucose. It also can be used to test alcohol in the blood since the normal glucose concentration is under $4.4 \mathrm{mM}$ or below $6.6 \mathrm{mM}[27]$.

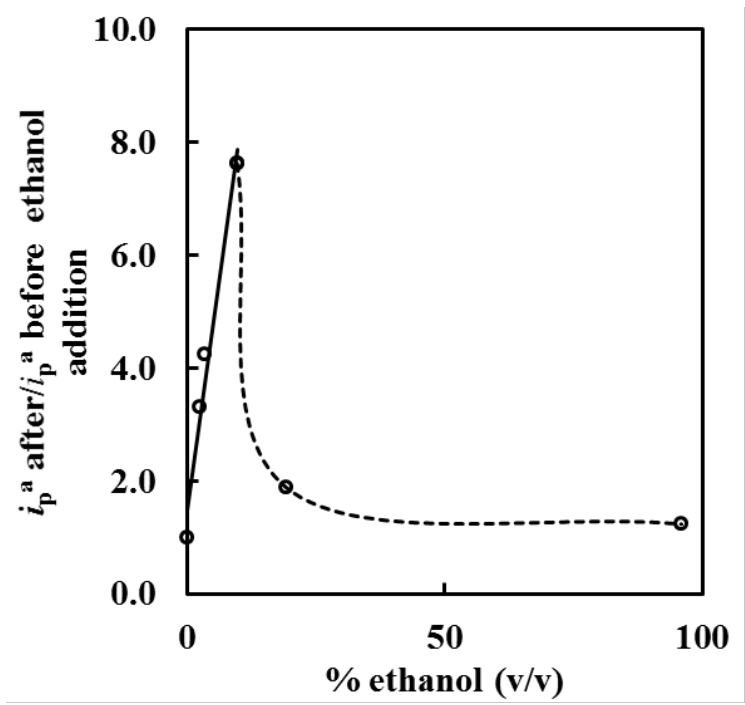

Fig. 7 Variations of the $i_{\mathrm{p}}{ }^{\mathrm{a}}$ after $/ \boldsymbol{i}_{\mathrm{p}}{ }^{\mathrm{a}}$ before ethanol addition with the ethanol concentration between $2.4 \%(\mathrm{v} / \mathrm{v})$ and $19.6 \%(v / v)$. Cyclic voltammograms recorded in PBS buffer solutions (pH 7) with $\mathrm{KCl}(100 \mathrm{mM})$ and with ethanol prepared in PBS buffer (pH 7) with $\mathrm{KCl}(0.1 \mathrm{M})$, at a screen printing electrode with a three electrode system configuration with an $\mathrm{Ag} / \mathrm{AgCl}$ reference electrode, a carbon counter electrode and a working electrode based in carbon ink (1.0 g) with AHD (14 mg). The best curve fit in the range of $2.4 \%-9.6 \%$ is $i_{p}{ }^{\text {a cat }}=0.664$ [ethanol] $+1.493, R^{2}=0.9735$. Each point is the average of two measurements made with different screen-printing biosensors. 


\section{Conclusions}

The main goal of this paper was to present a simple and economic biosensor fabrication procedure that permits the use of enzymes in the solid state and improve their stability. To prove this idea we mixed lyophilized powder of ADH with the carbon ink and used it to print the working electrode of a biosensor. The construction of a working electrode by simply mix carbon ink with ADH permits stabilizing the enzyme and allows obtaining an electrochemical reversible signal. This way it was possible to have stable redox signals of the ADH with this sensor, corresponded to peaks I and II (Fig. 2).

The observed electron transfer between the electrode-enzyme pair is a diffusion-controlled-process that occurs in the formal potential of $(-44 \pm 3) \mathrm{mV}$ vs $\mathrm{Ag} / \mathrm{AgCl}$. These biosensors also sense the presence of alcohol. On the basis of the above results, it's proposed that $\mathrm{ADH}$ can directly transfer electrons to the electrode surface of this sensor, enabling the ethanol diffusion from the solution to the electrode surface, which has enzymes. Having this in mind it is also possible to assume that the enzyme presents a stable open conformation which allows its functioning. The ethanol will bond directly to the zinc, via glutamic acid, and the catalysis will occur. We propose that the peaks III and IV (Fig. 3) correspond to another electron transfer process that is reversible, but it is not related to the catalysis. Our purpose is that the peaks III and IV are related to the reversible oxidation/reduction of the structural zinc.

The environment that surrounds the enzyme in the carbon ink, facilitate its stability and the permanence of the cofactor which are entrapped in the vicinities of the active site of the enzyme and does not leave the enzyme. The enzyme is enclosed in the carbon ink, which does not facilitate the escape of the cofactor by free-diffusion to the electrolyte.

The findings, published in this article suggest that this paper device permits the ethanol determination, in the range of 2.4-9.6\% (v/v) at $\mathrm{pH} 7$ and in the range of
2.4-19.2\% at $\mathrm{pH} 5$ in the presence of glucose (in concentrations lower than $25 \mathrm{mM}$ ).

These results encourage further investigations concerning the use of this fabrication procedure to study electron transfer mechanisms that involve redox proteins with more than a redox center and the use of this concept to develop biobatteries.

\section{References}

[1] Park, J., Yee, H., Lee, K., Lee, W., Shin, M. and Kim, T. 1999. "Determination of Breath Alcohol Using a Differential-Type Amperometric Biosensor Based on Alcohol Dehydrogenase.” Anal. Chim. Acta. 390: 83-91.

[2] Alpat, S., and Telefoncu, A. 2010. "Development of an Alcohol Dehydrogenase Biosensor for Ethanol Determination with Toluidine Blue O Covalently Attached to a Cellulose Acetate Modified Electrode.” Sensors 10: 748-64.

[3] Koyuncu, D., Erden, P., Pekyardimci, S., and Kiliç, E. 2007. "A New Amperometric Carbon Paste Enzyme Electrode for Ethanol Determination.” Analytical Letters 40: 1904-22.

[4] Bolivar, J., Rocha-Marín, J., Mateo, C., and Guisán, J. 2012. "Stabilization of a Highly Active but Unstable Alcohol Dehydrogenase from Yeast Using Immobilization and Post-immobilization Techniques.” Process Biochemistry 47: 676-86.

[5] Sekretaryova, A., Eriksson, M., and Turner, A. 2016. "Bioelectrocatalytic Systems for Health Applications." Biotechnology Advances 34: 177-97.

[6] Blanco, E., Foster, C., Cumba, L., Carmo, D., and Banks, C. 2016. "Can Solvent Induced Surface Modifications Applied to Screen-Printed Platforms Enhance Their Electroanalytical Performance?” Analyst 141: 2783-90.

[7] Nie, Z., Deiss, F., Liu, X., Akbulut, O., and Whitesides, M. 2010. "Integration of Paper-Based Microfluidic Devices with Commercial Electrochemical Readers." Lab on a chip. 10: 3163-9. DOI: 10.1039/c0lc00237b.

[8] Nie, Z., Nijhuis, C., Gong, J., Chen, X., Kumachev, A., Martinez, A., Narovlyansky, M., and Whitesides, M. 2010. "Electrochemical Sensing in Paper-Based Microfluidic Devices.” Lab on a chip 10: 477-83. DOI: 10.1039/b917150a.

[9] Santhiago, M., and Kubota, L. 2013. “A New Approach for Paper-Based Analytical Devices with Electrochemical Detection Based on Graphite Pencil Electrodes.” Sensores and Actuators B 177: 224.

[10] Costa, M., Veigas, B., Jacob, J., Santos, D., Gomes, J., Baptista, P., Martins, R., Inácio, J., and Fortunato. E. 2014. “A Low Cost, Safe, Disposble, Rapid and Self-sustainable 


\section{The Alcohol Dehydrogenase Example}

Paper-Based Platform for Diagnostic Testing: Lab-on-Paper.” Nanotechnology 25: 094006.

[11] Wang, Z., Etienne, M., Quilés, F., Kohring, G. W., and Walcarius, A. 2012. "Durable Cofactor Immobilization in Sol-Gel Bio-composite Thin Films for Reagentless Biosensors and Bioreactors Using Dehydrogenases." Biosens. Bioelectron. 15 (32): 111-7. doi: 10.1016/j.bios.2011.11.043.

[12] Neto, S., Forti, J., Zucolotto, V., Ciancanglini, P., and De Andrade, A. 2011. "The Kinetic Behavior of Dehydrogenase Enzymes in Solution and Immobilized onto Nanostructured Carbon Platforms." Process Biochemistry 46: 2347-52. DOI: 10.1016/j.procbio.2011.09.019.

[13] Tsai, Y-C., Huang, J-D., and Chiu, C-C. 2007. “Amperometric Ethanol Biosensor Based on Poly (Vinyl Alcohol)-Multiwalled Carbon Nanotube-Alcohol Dehydrogenase Biocomposite." Biosensors and bioelectronics 22: 3051-6.

[14] Manso, J., Mena, M.,Yáñez-Sedeño, and Pingarrón, J. 2008. “Alcohol Dehydrogenase Amperometric Biosensor Based on a Colloidal Gold-Carbon Nanotubes Composite Electrode.” Electrochimica Acta. 53: 4007-12.

[15] Schlager, S., Neugebauer, H., Haberbauer, M., Hinterberger, G., and Sariciftci, N. 2015. "Electrochemical Addressing of Immobilized Alcohol Dehydrogenase for the Heterogeneous Bioelectrocatalytic Reduction of Butyraldehyde to Butanol.” Chemcatchem 7: 967-71. DOI: 10.1002/cctc.201402932.

[16] Zhang, M., Mullens, C., and Gorski, W. 2007. "Coimmobilization of Dehydrogenases and Their Cofactors in Electrochemical Biosensors.” Analytical Chemistry 79: 2446-50. doi:10.1021/ac061698n.

[17] Leskovac, V., Trivić, S., and Peričin, D. 2002. "The Three Zinc-Containing Alcohol Dehydrogenases from Baker's.” FEMS Yeast Research 2 (4): 481-94.

[18] Baskar Raj, S., Ramaswamy, S., and Plapp, B. 2014. Yeast
"Alcohol Dehydrogenase Structure and Catalysis." Biochemistry 53: 5791-803.

[19] Magonet, E., Hayen, P., Delforege, D., Delaive, E., and Remacle, J. 1992. "Importance of the Structural Zinc Atom for the Stability of Yeast Alcohol Dehydrogenase." Biochemical Journal 287: 361-5. DOI: 10.1042/bj2870361.

[20] Santos, A., Freire, R., and Kubota, L. 2003. "Highly Stable Amperometric Biosensor for Ethanol Based on Meldola’s Blue Adsorbed on Silica Gel Modified with Niobium Oxide.” J. Electroanal. Chem. 547: 135-42.

[21] Santos, A. S., Pereira, C. A., Duran, N., and Kubota, L. T. 2006. “Amperometric Biosensor for Ethanol Based on Co-immobilization of Alcohol Dehydrogenase and Meldola's Blue on Multi-wall Carbon Nanotube.” Electrochim. Acta. 52:215-20.

[22] Wang, Z., Etienne, M., Poller, S., Schumann, W., Kohring, G. W., Mamane, V., and Walcarius, A. 2012. "Dehydrogenase-based Reagentless Biosensors: Electrochemically Assisted Deposition of Sol-Gel Thin Films on Functionalized Carbon Nanotubes." Eletroanalysis 24: 376-85. DOI: 10.1002/elan.201100574

[23] Marcus, R., and Sutin, N. 1985. "Electron Transfers in Chemistry and Biology." Biochim. Biophy. Acta. Rev. Bioenerg. 811: 265-322.

[24] Armstrong, F., Hill, H., and Walton, N. 1985. "Reactions of Electron-Transfer Proteins at Electrodes.” Q. Rev. Biophys. 18: 261-322.

[25] Baker, P., Britton, K., Fisher, M., Esclapez, J., Pire, C., Bonete, M., Ferrer, J., and Rice, D. 2009. “Active Site Dynamics in the Zinc-Dependent Medium Chain Alcohol Dehydrogenase Superfamily.” Proc. Natl. Acad. Sci. 106: 779-84.

[26] Stryer, L. 1995. In Biochemistry. Fourth edition, W. H. Freeman and Company. New York.

[27] Wang, J. 2008. "Electrochemical Glucose Biosensors." Chem. Rev. 108: 814-25. 